the words of Sir Edward Appleton, "objective fundamental research". The choice of subjects for "free' research is difficult and, when freedom is given, the temptation to pursue fascinating by-paths merely for the sake of exploration must be resisted. The Com. missioners hope that, by choosing staffs wisely and giving them the accommodation they need, it will be possible to build sound foundations.

In considering priorities after the Second World. War in the light of the principles laid down by the original Advisory Committee, the Commissioners have been advised by a special committee of which Sir John Graham Kerr is chairman. This committee discusses with representatives of the Association a memorandum on post-war development prepared by the Council. Its recommendations for the strengthening of both staff and equipment, especially in the fields of algology and bacteriology, have now been implemented to a considerable extent. For accommodation the Association has been exceptionally fortunate in finding the Ferry House, for it would otherwise have been necessary to remain for some five years at Wray Castle and then acquire land on which to build afresh.

\section{MANCHESTER COLLEGE OF TECHNOLOGY}

\section{EXTENSION OF THE DEPARTMENT OF MECHANICAL ENGINEERING}

$\mathrm{A}^{\mathrm{n}}$

FTER numerous recent discussions of plans for technical education at the higher levels, it may be refreshing to consider the way in which older provision has been developed in an endeavour to meet modern requirements. One such opportunity has been provided by the formal opening by Mr. Louis Mather on December 7 of the first part of the extension to the Manchester Municipal College of Technology, namely, that devoted to mechanical engineering.

The College, which was founded as a Mechanics Institute in 1824, has a double role, first as the major technical college in a wide regional scheme and dealing with subjects at an advanced level (higher national certificates, special and refresher courses, etc.), and secondly as incorporating the Faculty of Technology of the University of Manchester, with which it was integrated in 1903, and working for the Bachelor's, Master's and Doctor's degrees. The happy blending of these two functions, with marked advantages to both sides, is a major feature of the work of the College, and provides opportunities for developments, particularly in connexion with part-time activities.

Though the building completed in 1903 stands as a majestic monument to the courage and wisdom of its founders, provision was made for its growth, and the extension under construction, which will double the original size, forms an integral part of the whole: The section now being opened contains one very large single-storey laboratory, several smaller laboratories and stores, offices for members of the staff, and two drawing offices. Alternative accommodation is also provided for other departments, and will enable the Department of Mechanical Engineering to exterd considerably its laboratory facilities in the older building. Though schemes developed since the commencement of construction, delayed by the War, have necessitated changes in the purposes to be served by the various rooms, these have been skilfully adapted, and the general impression is one of fitness and great dignity. The full provision of offices for the staff and of a departmental committee room will not be available for a few months, but the facilities for quiet study and undisturbed consultation, so often overlooked, have received appropriate attention. It will be a little time yet before the full adjustments in the older building are completed, but there is no doubt that the final result will be very good.

Though the arrangements made in 1903 were considered very lavish, it is interesting to note that five laboratories and access to the College power-house were considered adequate to cover the various branches of mechanical engineering exclusive of craft-work, which is now dealt with elsewhere. In contrast, the later developments in engineering science and technology, and the refinements of modern methods, now call for more than four times this provision. For example, the measurement of the fundamental engineering quantities, such as size and form, temperature and heat, quantity, pressure and velocity of flow, which formerly occupied only small sections of general laboratories, now require separate provision and call for a degree of specialized knowledge and skill which, combined with work of a more traditional nature, make the selection and training of staff a far more formidable task than in earlier days. Nor can the requirements of modern industry in respect to such measurements be considered as essentially of a lower order than those for research. There are no separate research laboratories. It is a deliberate policy throughout the Department to bring teaching and research into close relationship so that the student becomes conscious of the refinements which can be made to the relatively simple apparatus which he himself uses, of the skill required in their handling, and of the concentration and care needed in planning, carrying out and completing an experimental investigation. Through the help given in the laboratories to industrialists seeking the advice and assistance of members of the staff, the student becomes aware also of the close relationship of his own task to the needs of the profession he is seeking to follow-a matter which too easily becomes obscured, to his considerable discouragement:

The equipment of the Department can be classed roughly under headings : (1) normal teaching equipment, (2) equipment for precise basic measurement, (3) special-purpose plant for specific investigations; but such a classification is far from satisfactory. For example, the precision measuring equipment may well be required to illustrate the logical development of the apparatus actually handled by the students, as well as being fundamental to research, while the systematic planning of research ensures that, through the medium of the equipment required, it will contribute to the work of the Department as a whole. It is interesting that research projects, though very frequently arising from discussions with the representatives of industry and receiving much help from them, are entirely under the control of the head of the Department, and that, in fact, suggestions for work which might be considered as routine or developmental are scarcely ever made.

The contribution of industry to the equipping of the Department, whether for teaching or research, is remarkable, both for its liberality and for the co-operative spirit in which it is made. It may take the form of raw material, a complete major unit of 
plant, or of a large number of items which together form a unified whole. A completely air-conditioned and automatically controlled wind tunnel for heat transfer tests is an example of the latter, sixteen firms having worked together to produce a unique plant of great value.

In addition to generous help from the local education authority, and from the University Grants Committee, the College has profited very greatly from the scheme for the acquisition of surplus government equipment in the development of which it played a leading part, and from loans from government departments.

In a Department which has been almost entirely equipped or re-equipped on a lavish scale within a few years, only a few sections can here receive special mention. The many problems relating to heat claim six laboratories, including extensive provision for the study of heat generation and transmission involving the use of a number of wind tunnels, of refrigeration and of instrumentation. The large new laboratory is devoted to the detailed examination of the various machining processes, to the structural and functional design of machine tools, and to advanced welding methods and the design of welded structures. The laboratory for the examination of the strength of materials contains much excellent equipment and has ample provision for the study of fatigue, and a very wide range of strain-measuring devices. A new laboratory for the study of problems in relation to hydraulic power transmission is being equipped to supplement the more normal work of the Mechanics of Fluids Laboratory. The excellence and range of equipment in the Engineering Metrology Laboratories place them in a unique position to aid in the development of the teaching of the subject up to the highest levels and to serve precise researches in many branches of engineering. Though less spectacular, the work of the Department on the close study of teaching methods in the laboratory and the teaching of machine design is of considerable interest.

The Department of Mechanical Engineering is very happily supported in its work by associated Depart. ments of Electrical Engineering, Metallurgy, Physics, Chemistry and Mathematics, to which it contributes in its turn.

The College can indeed be.congratulated on having achieved a unity of purpose by a process involving adaptability and constructive compromise, and for the part which it is playing in the development of the study and teaching of technology in Great Britain.

\section{COMMITTEE ON INDUSTRIAL PRODUCTIVITY}

\section{REPORT FOR 1949}

$\mathrm{T}$

HE second report of the Committee on Industrial Productivity*, which covers the activities of the Committee during 1949, is also the final report, for in it the Committee reaches the conclusion that no further purpose would be served by its continuance, as the tasks hitherto entrusted to it can in future be better performed by other existing bodies. In a written statement to Parliament on July 24 the

- Second Report of the Committee on Industrial Productivity. (Cmd. 7991.) Pp. 10. (London: H.M. Stationery Offce 1950.) 4d. net.
Lord President of the Council announced that the Government had accepted the Committee's own recommendation for its discharge; the Lord President said further that, since the time when the Committee and its panels were set up as a short-term measure to bridge the gap between the winning and application of knowledge in both the natural and the social sciences, the importance of increasing industrial productivity has become generally accepted and productivity is increasing at a most encouraging pace.

The Committee in its report refers to the work of the Anglo-American Council on Productivity which has already sent twenty-four productivity teams, representative of the management-, technical- and workshop-levels in selected sectors of British industry, to visit the corresponding sectors of industry in the United States, and to the action taken by more than twenty trade associations, encouraged by the Engineering Advisory Council of the Ministry of Supply, to work out mutual aid schemes or increase efficiency and reduce costs. The General Council of the Trades Union Congress has decided to establish a productivity department and has asked the British Institute of Management, which is steadily increasing its activities, to prepare a handbook on productivity techniques for workshop representatives, etc.

Besides work on standardization and simplification in industry and the establishment of the National Research Development Corporation in June 1949, good progress has been made in the development of joint consultation and works information in industry, while the Technicel Assistance Scheme of the Economic Co-operation Administration has made possible visits to the United States by a number of specialists and technicians from Government departments and research associations to examine particular problems in the United States from the point of view of increasing production and efficiency in Great Britain. Arrangements can also be made for teams of experts from a number of countries to go to the United States to study, for the benefit of European industry as a whole, particular advances in American technology, and the United Kingdom has already participated in several such projects.

Available figures indicate that productivity has been steadily increasing during the past two years, and the Committee on Industrial Productivity regards it as reasonable to assume that the increased production is due chiefly to an increased annual output per worker. It emphasizes that, while.the part played by science and technology in promoting productivity is clear and well recognized, but subject for achievement to such conditions as an ample supply of power and of capital for improvement, it is doubtful whether the importance of the human side of the problem is yet sufficiently appreciated. Technical improvements cannot achieve their full effect if the necessary human relations are lacking. The Committee believes that scientific investigation can help the promotion of good human relations, and that it is necessary to develop the social sciences side by side with the physical sciences ; the approach to the human aspects of this problem must not be too narrow, but should be based on a study of all relevant parts of social environment. Furthermore, the Committee is of the opinion that it is not always enough, in considering possible improvements in productivity, to examine human factors alone or in isolation; human and technological factors in industry tend to be inter. mingled or intimately related and to react so 